\title{
A Study on the Bilge Keels
}

\author{
(Part 2. Full Sized Model Experiment)
}

By Norio Tanaka, Member*

and Hiroshi Kitamura, Member*

\begin{abstract}
In the present paper an empirical formula (1) for the fin resistance is obtained after analysing the results of the rolling experiments on the action of a full-sized bilge plate. And a method of approximate calculation of the rolling resistance to actual ships by the bilge keels is found by adding the above-mentioned fin resistance to the surface resistance calculated by the method given in the first report.

\section{Introduction}

There are only a few experimental studies about rolling for actual ships on the action of the bilge keels (hereafter, to be shortened B. K.) and they are found only in the papers by White ${ }^{1)}$, Spear ${ }^{2)}$ and $\mathrm{Gawn}^{3)}$ and others. In recent years, considerably wide experiments of $\mathrm{B}$. K. of actual ships were carried out by the 17 th Research Committee of the Shipbuilding Research Association of Japan. The authors engaged themselves in experimental studies on the action of $B$. $K$. with reference to the two dimensional model ships and a full-sized cylinder model. The former study was already published in the first report ${ }^{4}$ and in the present paper the latter experiment is to be reported. A method of approximate estimation of the rolling resistance by $B . K$. to actual ships is devised from this experimental result and its applications to actual ships are shown.
\end{abstract}

\section{Experiment}

It was found by the two dimensional model experiments that the work done $A_{F}$ due to the fin resistance is almost independent of the radius of bilge circle $R^{* *}$, the draft $d$ and the aspect ratio of B.K., so in the full-sized model experiment a cylindrical surface is used as a model as shown in Fig. 1. The forces acting on the forced arm C. R. are measured with or without B.K. in the forced rolling about the center of the cylindrical surface, and the fin resistance, hence $A_{F}$, is obtained from the difference between those forces.

The rolling experiments are carried out by changing the width of B.K. b $(0.30,0.212,0.105$

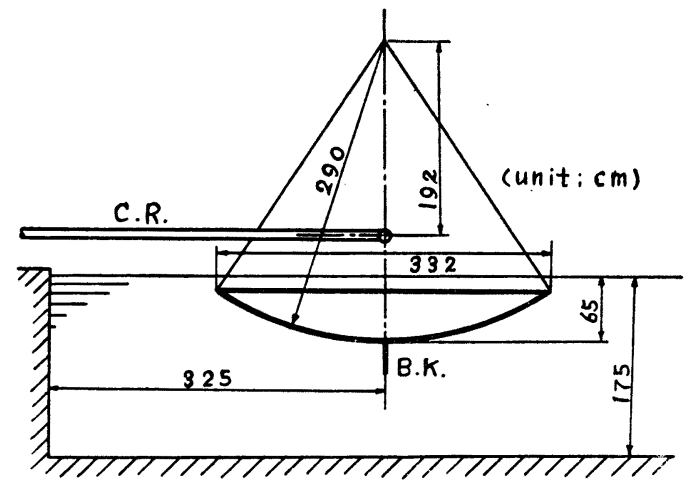

Fig. 1 $\mathrm{m})$, the rolling period $\mathrm{T}\left(7,10,13 \mathrm{sec}\right.$ ) and the amplitude $\theta_{0}(17.3,10.8,7.85 \mathrm{deg}$. $)$ one another, while the length of B.K. $l(=2.89 \mathrm{~m}$ ) is constant (the width of tank being $2.95 \mathrm{~m}$ ).

Received December 30, 1957

* Department of Naval Architecture, Faculty of Engineering, University of Osaka Prefecture, Japan

** See Appendix 
The following empirical formula is obtained as the result of the experiments of the fin resistance,

$$
A_{F}=0.384 b l \theta_{0}^{2 \cdot 5} T^{-1 \cdot 6} r^{2 \cdot 6},(\mathrm{~m}, \mathrm{~kg}, \mathrm{sec}, \mathrm{deg} \text {; units) }
$$

where, $r$ shows the average distance from the rolling axis to the center of $\mathrm{B}$. K.

Therefore, it is found that $A_{F}$

i) is proportional to an area of the bilge plate, and

ii) is also proportional to the 1.6 th power of the absolute velocity of the bilge plate.

Here, the wave making resistance due to the bilge plate is found to be no more than several percent of the fin resistance. (By using the measured wave-height, the wave making resistance is calculated, assuming the wave to be long enough.)

\section{Application to Actual Ships}

(1) It is assumed that $A$ which is the work done during a single swing against the resistance by B.K. to an actual ship is got from the sum of the $A_{F}$ calculated by the formula ( 1 ) and the As

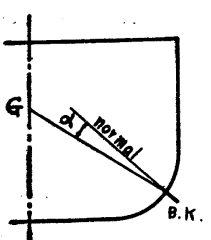

Fig. 2 . estimated by the same method as in the case of the model ship. There may be many unsolved problems to apply these $A_{F}$ and $A_{S}$, which are both the resistances for the two dimensional ship, to an actual three dimensional ship, but here, for the present, what is called the strip method is adopted. When the straight line that joins the rolling axis $G$ and the center of B. K. makes an angle $\alpha$ with the surface of the bilge plate as shown in Fig. 2, $A_{F}$ is assumed to be given by

$$
A_{F}=0.384 b l \theta_{0}^{2 \cdot 5} T^{-1 \cdot 6} r^{2 \cdot 6} \cos \alpha .
$$

Now, $A_{S}$ is calculated on the assumption given in the first report. The value of $A_{S 0}$ is given as a function of the sectional area coefincient $C$, the half breadth $\mathrm{B} / 2$ and the draft $\mathrm{d}$ in Figs. $3 \sim 5$, (The ships used in the above calculation have no rise of floor. where,

$$
\begin{aligned}
A_{S} & =\left(A_{S 0} / r b\right) \times A_{F} \\
C & =\text { sectional area coefficient }=\text { sectional area } / \mathrm{Bd}, \quad O G=d-K G .
\end{aligned}
$$

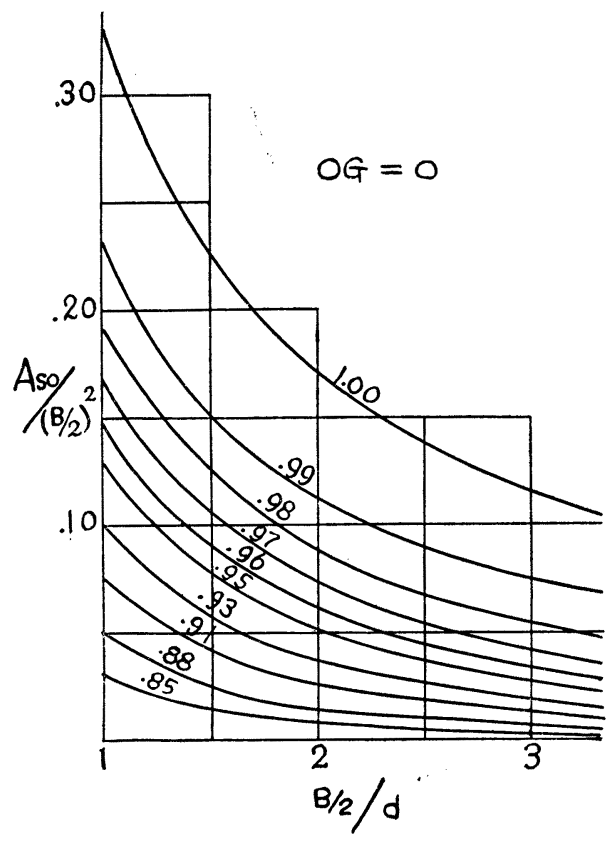

Fig. 3

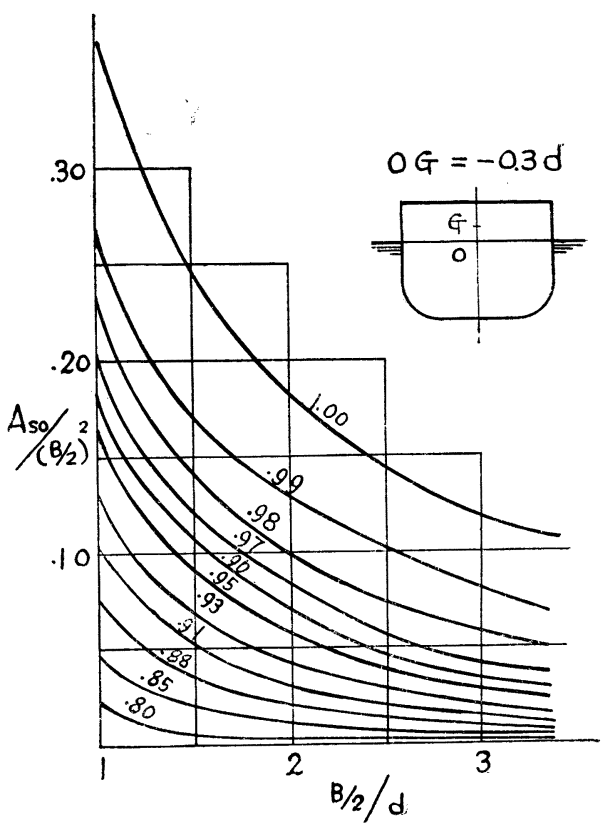

Fig. 4 


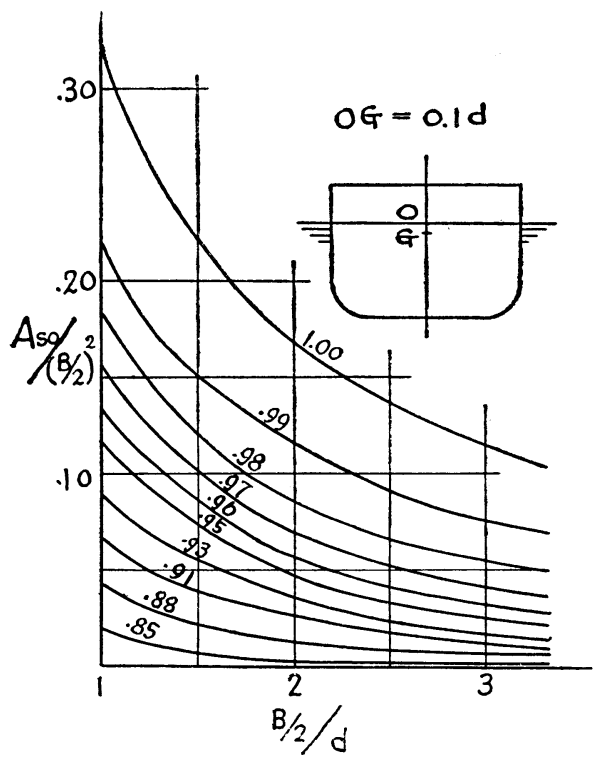

Fig. 5

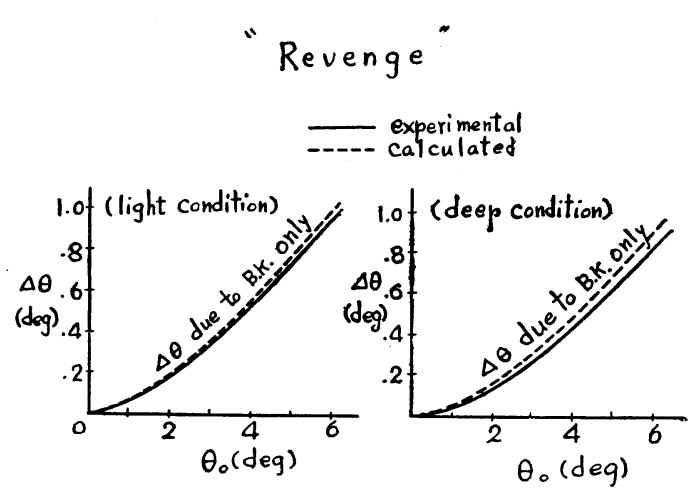

Fig. 6

And according as $O G$ increases $A_{S 0} /(\mathrm{B} / 2)^{2}$ decreases linearly when $(B / 2) / d$ is constant.

\section{(2) Examples}

The decrement of roll per swing due to B.K. only is calculated by the above-mentioned method for actual ships, and when it is compared with

experiments for actual ships the results will be such as shown in Figs. 6 9. The principal items of actual ships are shown in the Table. Fig. 6 is for the "Revenge" and Fig. 7 for the "Oregon." Perfect body plans of these ships can not be found, and the midship section of the "Revenge" and the sections at the midship and the end of B.K. for the "Oregon" are given in the literatures 1) and 2), so the other sections are estimated appropriately from the ship of the same type. In the same way the value of $K G$ of both ships is estimated, but it exerts little influence upon the $A_{F}$. (the effective radius $r$ is given). Fig. 8 and 9 show the results of the ships on which the rolling experiments are carried out by the 17 th Research Committee of the Shipbuilding Research Association of Japan. Fig. 8 is for the $23 \mathrm{M}$ typed patrol boats and Fig. 9 for the $800 \mathrm{G}$. T. typed passenger ship. Experiments are made with two kinds of B.K. for the latter and never conducted without B. K. Therefore, the residuals for the two kinds of B. K. obtained by subtracting the calculated $\Delta \theta$ due to $\mathrm{B}$. K. only from the experimental

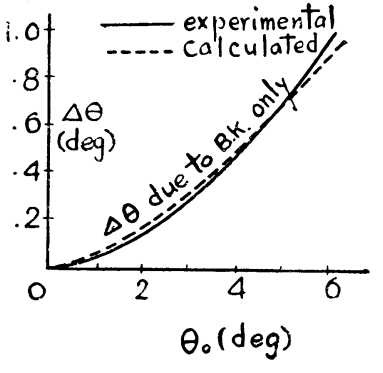

Fig. 7 $\Delta \theta$ due to total resistance are compared with other.

The calculated values agree fairly with the experimental results for the "Revenge" and the "Orfgon" Table

\begin{tabular}{|c|c|c|c|c|c|c|c|}
\hline Name of & f Ship & $L(\mathrm{~m})$ & $d_{m}(\mathrm{~m})$ & $G M(\mathrm{~m})$ & $W$ (ton) & $T(\mathrm{sec})$ & $b \times l\left(\mathrm{~m}^{2}\right)$ \\
\hline \multirow{2}{*}{ Revenge } & light cond. & \multirow{2}{*}{115.82} & 7.93 & 1.002 & 13,370 & 16.80 & \multirow{2}{*}{54.35} \\
\hline & deep cond. & & 8.52 & 1.177 & 14,620 & 15.50 & \\
\hline \multicolumn{2}{|l|}{ Oregon } & 106.07 & 7.07 & 0.914 & 9,790 & 15.66 & 38.5 \\
\hline \multirow{2}{*}{ Patrol Boat } & I & \multirow{2}{*}{22.00} & 1.351 & 1.218 & 56.90 & 3.50 & \multirow{2}{*}{$0.30 \times 6.80$} \\
\hline & F & & 1.271 & 1.398 & 52.43 & 3.60 & \\
\hline \multirow{2}{*}{ Passenger } & New B.K. & \multirow{2}{*}{57.00} & 2.41 & 1.130 & 597.1 & 7.35 & $0.65 \times 25.8$ \\
\hline & Old B.K. & & 2.48 & 1.068 & 596.0 & 7.86 & $0.35 \times 23.4$ \\
\hline
\end{tabular}




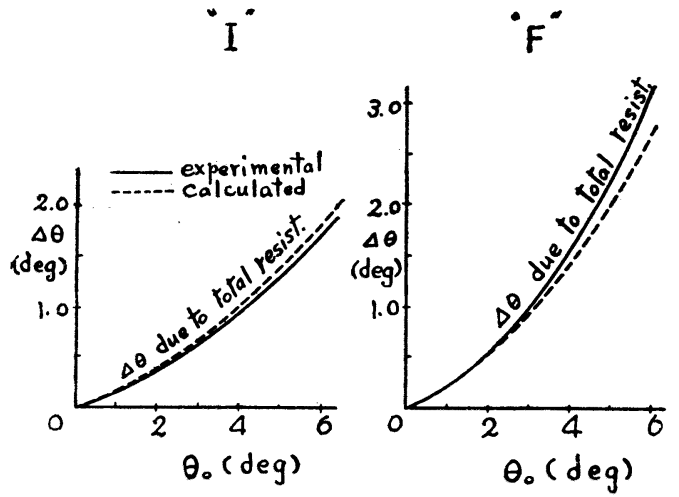

Fig. 8

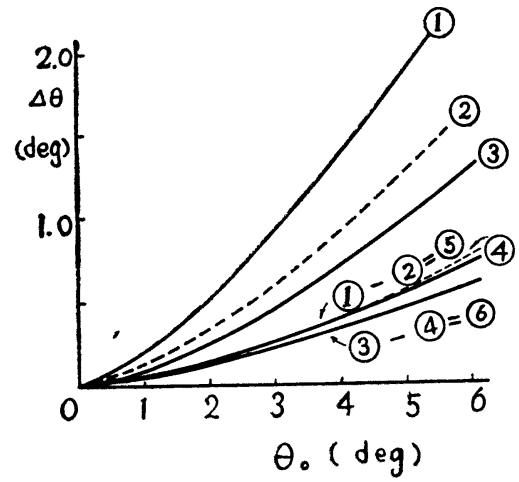

Fig. 9

as shown in Figs. 6 \& 7 in these examples.

In Fig. 9,

curve (1) ; experimental $\Delta \theta$ due to total resistance, new B.K.

(2) ; calculated $\Delta \theta$ due to B.K. only, new B.K.

(3) ; experimental $\Delta \theta$ due to total resistance, old B. K.

(4); calculated $\Delta \theta$ due to B.K. only, old B.K.

(5) ; (1)-(2), $T=7.86 \mathrm{sec}$. (modified)

(6) ; (3)-(4), $T=7.86 \mathrm{sec}$.

When the curves (5) and (6) are compared with each other in this figure, which is for passenger ship, it is found that the calculated values are appropriate. Though the influence of the bar keel of the $23 \mathrm{M}$ typed patrol boat upon B. K. must be considered, and accordingly the calculated curves may come down a little lower in Fig. 8, it can be said that the above-mentioned method of approximate calculation for these kind of ships is almost satisfactory.

\section{Closing Remarks}

A method of approximate calculation of the rolling resistance by the bilge keels to actual ships is found after analysing the experimental results on the action of a full-sized bilge plate, and applying this method to actual ships they succeeded in getting near to the anticipated result.

But the relation between the ship form and the rolling resistance on the action of $B$. $K$., and the more detailed study when this method is applied to actual ships will be reported later.

The authors wish to express their heartfelt thanks to Prof. T. Hishida for his helpful suggestion.

\section{Ref erences}

1) White, Sir W. H. ; "Notes on Further Experience with First-Class Battleships” TINA 1895,

2 ) Spear, Lawrence ; "Bilge Keels and Rolling Experiments U.S.S. Oregon" TSNAME 1898,

3) Gawn, R. W. L. ; "Rolling Experiments with Ships and Models in Still Water" TINA 1940,

4 ) N. Tanaka \& T. Hishida; A Study on the Bilge Keels (Part 1. Two Dimensional Model Experiments) Journal of the Soc. of Nav. Arch. of Japan, Vol. 101, 1957.

\section{Appendix}

In the previous paper it is reported that $A_{F}$ has almost no relation with the radius of bilge circle $R$, but more experiments concerning this problem must be added here. $A_{F}$ is obtained by the same method as reported in the Part 1 (See Part 1, Fig. 3) under the condition that $r$ is constnt, the rolling period $T=2 \mathrm{sec}$. and $b=3 \mathrm{~cm}$ for four model ships as shown in Fig. 10. The fin resistance becomes 
larger in some degree where $R$ is small as shown in Fig. 11.

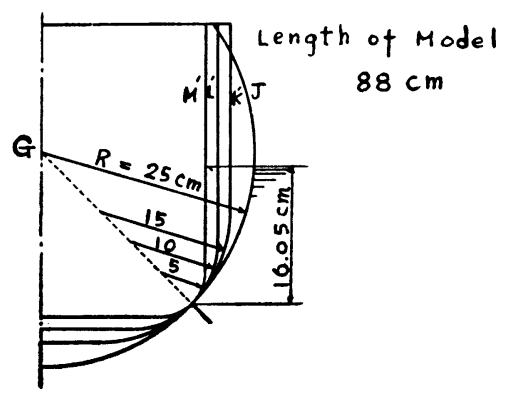

Fig. 10

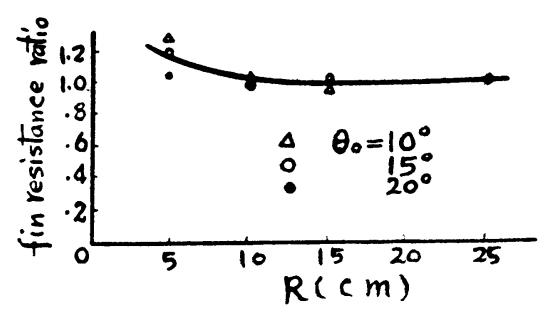

Fig. 11 